\title{
Compromiso militante y producción historiográfica. Hernán Ramírez Necochea y Julio César Jobet (1930-1973)
}

\author{
Nicolás Dip \\ (D) https://orcid.org/oooo-0001-6565-7319 \\ Colegio de Estudios Latinoamericanos \\ Facultad de Filosofía y Letras \\ Universidad Nacional Autónoma de México, México \\ nicolasdip@sociales.unam.mx
}

Gorka Villar Vásquez, Compromiso militante y producción historiográfica. Hernán Ramírez Necochea y Julio César Jobet (1930-1973), Santiago de Chile, Editorial Universitaria, 2021.

Un camino para reseñar un libro es abordarlo a partir de un conjunto de consignas que sintetizan las problemáticas o preguntas con que busca dialogar el autor. El trabajo de Gorka Villar Vásquez Compromiso militante y producción historiográfica. Hernán Ramírez Necochea y Julio César Jobet (1930-1973) puede indagarse desde tres ideas fuerza.

\section{I}

Escapar a las hipótesis de la pérdida de especificidad es la primera consigna. La misma lleva al corazón de un libro que reflexiona sobre las relaciones entre el "compromiso militante" y la "producción historiográfica", es decir, en el ya clásico debate entre política e intelectuales en la historia reciente de América Latina. En este punto, la operación historiográfica de Villar Vásquez, como integrante de las camadas más jóvenes de investigadoras e investigadores chilenos, es desmarcarse de un enfoque recurrente en estas temáticas, el cual es sostenido por algunos ex

\section{cc) (i) (8)}

4.0 Internacional

Secuencia. Reseñas, 2021

http://secuencia.mora.edu.mx
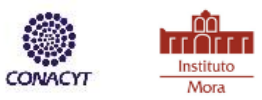


\section{Nicolás Dip}

protagonistas de la época, en especial de los años sesenta y sesenta, que luego se convirtieron en reconocidos intelectuales. ${ }^{1}$

Esta visión puede retratarse como las hipótesis de la "pérdida de especificidad". Su idea es que las formas y contenidos que transitaron los grupos politizados, partidizados y radicalizados del campo intelectual no hicieron más que disolver las problemáticas particulares de ese ámbito. Desde este razonamiento, la primacía de la política en la historia reciente de América Latina, sobre todo en los albores de los setenta, fue directamente proporcional a la pérdida de debates específicos sobre lo intelectual.

Si se matizan este tipo de encuadres, puede encontrarse un camino de interpretación diferente que no consiste en negar la política en pos de los debates culturales, sino en entender experiencias y procesos complejos donde esas dimensiones aparecen en tensión. Esa es la operación fundamental que realiza Villar Vásquez cuando analiza de manera integral las prácticas militantes y las producciones historiográficas del historiador comunista Hernán Ramírez Necochea (1917-1979) y del historiador socialista Julio César Jobet (1912-1980). La pesquisa se despliega entre 1930, década en que ambos comenzaron tanto sus estudios de Pedagogía en Historia y Geografía en la Universidad de Chile como su militancia en sus respectivos partidos políticos, y 1973, año del golpe de Estado contra el gobierno de la Unidad Popular encabezado por Salvador Allende. Ese desenlace llevó a Ramírez Necochea al exilio en Francia, donde finalmente murió, y a Jobet a una permanencia en Chile bajo protección diplomática, hasta su fallecimiento al finalizar la década.

En este marco, el libro plantea un doble movimiento. Por un lado, indaga cómo la práctica militante influyó en la producción historiográfica de Ramírez Necochea y Jobet, pero a la vez cómo sus operaciones intelectuales contribuyeron a la legitimación de los fundamentos ideológico-identitarios y los proyectos del Partido Comunista y el Partido Socialista de Chile. En este planteo, práctica política y práctica intelectual van de la mano e incluso las referencias históricas de Villar ${ }^{1}$ Entre ellos se puede mencionar al mexicano Sergio Zermeño (1978), el chileno Manuel Antonio
Garretón (1985) y los argentinos Oscar Terán (1992) y Beatriz Sarlo (2001). 


\section{Nicolás Dip}

Vásquez en ocasiones recuerdan a la indicación que hace la argentina Silvia Sigal (1991) en su clásico trabajo Intelectuales y poder en la década del sesenta, donde sostiene que inclusive los posicionamientos antiintelectuales de los militantes más partidizados de esos años eran operaciones intelectuales.

En el libro pueden encontrarse diversas lecturas históricas de Ramírez Necochea y Jobet donde se vislumbra ese doble movimiento, por ejemplo, en sus diatribas sobre la independencia de Chile y la Guerra Civil de 1891 o la figura de José Manuel Balmaceda, pero hay una parte donde sus divergencias explicitan claramente cómo sus prácticas intelectuales estaban en vinculación con los proyectos políticos de sus respectivos partidos. Esa sección del libro recuerda lo que dice Emilio de Ípola (2007) en Althusser, el infinito adiós, cuando sostiene que el intelectual del comunismo francés desarrollaba una especie de "lectura sintomal", dado que prestaba atención a las lagunas en los textos, a sus contradicciones, a sus cosas no dichas o dichas de manera singular.

Eso es un poco lo que hace Villar Vásquez al detectar que en un párrafo a pie de página del libro que publica Ramírez Necochea en 1956 titulado Historia del movimiento obrero en Chile, siglo XIX se refería a un tema que aparentemente no tenía ninguna relación con el marco temporal del escrito ni con sus objetivos. Esa referencia era justamente una crítica al libro de Jobet, Recabarren. Los orígenes del movimiento obrero y del socialismo chileno que acababa de llegar a sus manos y que le hacía pensar a Ramírez Necochea que el socialista estaba "ofuscado" y que no hacía más que mostrar sus "malas intenciones" de querer justificar que no existía ningún nexo entre la figura de Luis Emilio Recabarren y la fundación del Partido Comunista de Chile.

Más allá de las valoraciones de los propios actores de época, estos cruces sobre

figuras históricas como Recabarren muestran los esfuerzos intelectuales que implicaba la construcción o invención de tradiciones históricas (al estilo de Eric Hobsbawm, pero también al de Raymond Williams en Marxismo y literatura) para justificar los orígenes y los planteamientos políticos de sus partidos. 
II

La segunda consigna que sintetiza los debates del trabajo de Villar Vásquez es libros sí, revistas y universidades también. Cuando su investigación aborda el itinerario político-intelectual de Ramírez Necochea y Jobet muestra los distintos anclajes donde se materializaba la práctica intelectual en buena parte del siglo XX. Aunque en sus páginas predomina el análisis de los libros de ambos historiadores chilenos, tampoco están ausentes sus intervenciones en revistas y en las universidades.

Las revistas son un tópico fundamental como espacio en que se producía, en términos de Claudia Gilman (2003), la conversión del escritor en intelectual. En este asunto, el libro muestra las tensiones políticas e intelectuales de Ramírez Necochea y Jobet. Por ejemplo, en una parte Villar Vásquez sostiene que a pesar de que el Partido Socialista de Chile adoptó una amplia base multiclasista que se reforzaba con "símbolos mestizos", como el hacha araucana sobre un mapa de América Latina enmarcada en un círculo de colores rojo y blanco, queda abierto el interrogante por el escaso interés que manifestó Jobet por la historia del pueblo araucano en los años treinta.

A entender del propio autor, la raigambre latinoamericanista del Partido Socialista hubiese exigido una búsqueda más profunda en ese aspecto. No obstante, su libro también señala que casi treinta años más tarde, Jobet atribuiría cierta importancia a los símbolos de la historia indígena. Tras el triunfo de la revolución cubana de 1959, el historiador y un grupo de militantes socialistas fundó la revista Arauco, la cual se proponía rescatar justamente "la raíz misma de la nacionalidad chilena y las remotas luchas populares".

Por otra parte, en relación con los itinerarios universitarios de Ramírez Necochea y Jobet, el libro deja en suspenso un conjunto de experiencias protagonizadas por ambos intelectuales que podrían indagarse en futuras investigaciones. Una cuestión relevante que se podría profundizar es el protagonismo de la Facultad de Filosofía y Educación, bajo el liderazgo de Ramírez Necochea, en la Reforma de 1968 en la Universidad de Chile. El propio historiador fue un personaje central en la definición de un discurso sobre universidad en el comunismo chileno. En 1964 ya había publicado el libro El Partido Comunista y la 


\section{Nicolás Dip}

Universidad en ediciones de la revista Aurora y al poco tiempo tuvo influencia en el peso político que congregó la Juventud Comunista en la Universidad de Chile. En 1969, la “jota” encabezó la lista de la Unidad Popular que destronó a los demócratas cristianos de la conducción de la Federación de Estudiantes de Chile (FECH) tras catorce años de predominio. Ese triunfo debe leerse como unos de los antecedentes de la elección de Allende en 1970 como presidente de la nación, bajo esa misma coalición de izquierda.

III

Las categorías pueden encubrir petrificaciones arbitrarias es la tercera consigna en la que se sintetiza el libro. Villar Vásquez retoma de manera crítica el concepto de "historiografía marxista clásica" que propuso Gabriel Salazar a su vuelta de Inglaterra en los años ochenta, en una ponencia que hacía un balance de la producción historiográfica de los historiadores Jobet, Ramírez Necochea, Marcelo Segall (1920-2000), Femando Ortiz (1922-1976) y Luis Vitale (1927-2010). No obstante, aunque el libro esboza algunos cuestionamientos, al final termina manteniendo el concepto de "historiografía marxista clásica" para hacer referencia a una corriente que se afianza en los años cincuenta, cuyo denominador común fue la dedicación al estudio de la clase trabajadora organizada desde una perspectiva política. Esta tarea se realizó especialmente a través de trabajos de síntesis que buscaban una interpretación general del proceso histórico chileno, con el objetivo de destacar sus rasgos fundamentales.

Lo que queda como interrogante en el libro de Villar Vásquez es si este tipo de categorías y caracterizaciones generales no atentan un poco contra la posibilidad de entender las particularidades de intelectuales comunistas y socialistas chilenos, por ejemplo, la compleja formación intelectual de Jobet y Ramírez Necochea en diálogo con historiadores liberales, como el paradigmático Guillermo Feliú Cruz. En este asunto, una de las citas más productivas del libro que advierte contra esos riesgos es la de Michel Espagne (1994): "la catalogación de grupos humanos que no se pone en tela de juicio puede despertar la sospecha de una petrificación arbitraria”.

La cita a su vez recuerda los inconvenientes que muchas veces transitan algunos estudios de la historia reciente latinoamericana, al retratar los años sesenta 
y setenta como un momento de irrupción y predominio de una nueva izquierda sobre los sectores tradicionales del Partido Socialista y el Partido Comunista. De esta manera, la época queda retratada de forma esquemática y explicada en un discurso unidireccional donde la revolución cubana es un parteaguas que deja atrás una izquierda moderada, legalista y tradicional, frente a otra que adopta líneas heterodoxas y es más tendiente a la acción directa y la lucha armada. Justamente y aunque no sea uno de sus propósitos, el libro de Villar Vásquez alerta sobre lo poco productivas que son ese tipo de imágenes para abordar la experiencia chilena, más si se tiene en cuenta la posterior radicalización de sectores del Partido Socialista en los albores de los setenta.

En definitiva, el trabajo de Villar Vásquez deja abierto un conjunto de senderos que restan recorrer en la historia reciente de América Latina, como aquellos donde se encuentra el interrogante sobre si los conceptos de "historiografía marxista clásica" o de "nueva izquierda" no se convierten en limitantes a la hora de proponer estudios y desafíos historiográficos desde las camadas más jóvenes de investigadoras e investigadores, quienes aún tienen mucho para aportar en la discusión con las lecturas "clásicas".

\section{Referencias}

De Ípola, E. (2007). Althusser, el infinito adiós. Buenos Aires: Siglo XXI.

Espagne, M. (1994). Sur les limites du comparatisme en histoire culturelle. Genèses, 17, 112-121. https://www.persee.fr/doc/genes_1155-3219_1994_num_17_1_1266

Garretón, M. A. y Martínez, J. (1985). Biblioteca del movimiento estudiantil. Santiago de Chile: Ediciones Sur.

Gilman, C. (2003). Entre la pluma y el fusil: debates y dilemas del escritor revolucionario en América Latina. Buenos Aires: Siglo XXI.

Sarlo, B. (2001). La batalla de las ideas. Buenos Aires: Ariel.

Sigal, S. (1991). Intelectuales y poder en la década del sesenta. Buenos Aires: Puntosur.

Terán, O. (1991). Nuestros años sesenta. Buenos Aires: Punto Sur.

Zermeño, S. (1978). México: una democracia utópica. El movimiento estudiantil del 68. México: Siglo XXI. 